Ильме РОХТЛА, Лиа ПААЛЬМЕ, М. ГУБЕРГРИЦ

\title{
ФОТОИНИЦИИРОВАННОЕ РАЗЛОЖЕНИЕ НЕКОТОРЫХ ПОЛИЦИКЛИЧЕСКИХ АРЕНОВ, СОРБИРОВАННЫХ НА ДИСПЕРСНОМ ТВЕРДОМ НОСИТЕЛЕ
}

Загрязнение атмосферного воздуха полициклическими ароматическими углеводородами (ПАУ), среди которых многие канцерогенны, как правило связано с выбросами в окружающую ореду пыли, т. е. частиц твердого материала разной дисперсности. Известно, что до $85 \%$ бенз (а)пирена (БП) индикаторного канцерогенного ПАУ, попадающего в атмосферу, содержится в тонкой фракции пыли с размерами частиц 2,3 мкм [1]. Некоторая часть пыли, постепенно оседая на различных расстояниях от места выброса, служит источником загрязнения почвы, водоемов, растительности. Значительная часть связанных с пылью ПАУ, по данным для БП до $50 \%$, успевает подвергнуться в атмосфере разложению под инициирующим действием УФ-компонентов солнечного излучения $\left[{ }^{2}\right]$. В подтверждение сошлемся на $\left[{ }^{3}\right]$, в которой охарактеризовано разложение БП на твердом носителе.

Следует иметь в виду, что БП не единственный компонент смеси ПАУ в пылевых загрязнениях воздуха и содержится в концентрации, примерно такой же, ккак и у других пяти-шестичленных аренов, но оказывается во много раз ниже содержания молекул меньшего размера [4]. В связи с вышеизложенным основной задачей настоящего исследования была предварительная оценка возможных изменений концентрации некоторых ПАУ, закрепленных на дисперсных твердых загрязнителях, под действием важнейших физико-химических агентов (инициирующим влиянием УФ-излучения и взаимодействием с кислородом воздуха и продуктами его возбуждения), т. е. их относительной реакционной способности при имитации процесса самоочищения среды в подобной системе.

\section{Методика и объекты исследования}

В основной части эксперимента в качестве дисперсного носителя была выбрана окись алюминия (по Брокману, нейтральная), которую наносили тонким слоем, толщиной 1 мм, на стеклянную пластину размером $130 \times 180$ мм. Пробу исследуемого ПАУ, растворенного в этаноле или бензоле, наносили в виде узкой полосы определенного размера на стартовую линию пластины, причем в каждом опыте на 12 окиси алюминия в среднем приходилось $8,8 \cdot 10^{-8}$ моль или 22,3 мке, что соответствует 1,8 мка/с $\mathrm{M}^{2}$. Напомним, что по данным $[1,4]$, содержание БП в пыли при одном из обследований крупных городов колеблется от 0 до 17 мкг/2, а величина атмосферного выпадения оценивается для БП в $0,04-1,8$ мка $/ \mu^{2}$ в месяц.

В качестве источника излучения иопользован весь поток ртутно-кварцевой лампы высокого давления. Суммарная интенсив- 
ность излучення, определенная актинометрически по [ $\left.{ }^{5}\right]$, составила $0,8 \cdot 10^{17} \kappa в а н т / м \Omega \cdot c$. Излучатель помещали над реакционной пластиной на расстоянии 250 мм. Длительность облучения в каждом эксперименте варьировали от 1 до 30 мин, опыты проводили при комнатной температуре. Остаток непрореагировавшего ПАУ определяли путем разделения вещества на той же пластине в восходящем потоке, с иопользованием в качестве растворителя смеси хлороформ - петролейный эфир $1: 9$. Место нахождения его на пластине обнаруживали по флуоресценции в УФ-свете. После элюирования этанолом (для бенз(е) пирена и хризена употребляли бензол) концентрацию ПАУ в растворе определяли спектрофотометрическим методом на «Specord UV-VIS» (ГДР) по выбранному максимуму спектра поглощения, учитывая фон. Перечень подвергнутых изучению ПАУ, их структурные формулы и основные результаты эксперимента приведены в таблице.

\section{Результаты исследования}

На рисунке приведены кривые, характеризующие изменения во времени количества исходных ПАУ в системе. В отличие от екорости фотоинициированного окисления тех же ПАУ в органических жидкостях скорость превращения аренов в ходе опыта меняется от высокой в начале эксперимента до ассимптотически затухающей (примерно, после 15 мин облучения). Это явление представляется естественным при учете неизбежного экранирующего влияния слоя носителясорбции некоторой части молекул углеводорода в порах частиц.

При использовании в качестве твердого ноेсителя силикагеля разной дисперсности за 20 мин экопозиции достигается степень превраще-

Кинетика фотоинициированного окисления исследованных ПАУ на твердом носителе

\begin{tabular}{|c|c|c|c|c|c|}
\hline 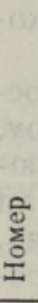 & $\begin{array}{c}\text { Наименование и структурная } \\
\text { формула }\end{array}$ & 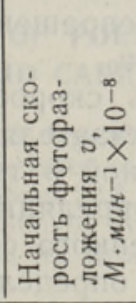 & 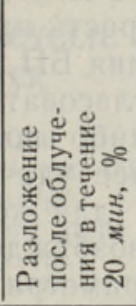 & 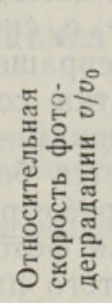 & 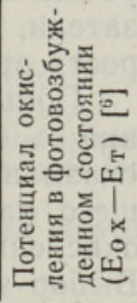 \\
\hline 1. & Антрацен $a$ & 4,23 & 84,5 & 13,64 & $-0,73$ \\
\hline 2. & Пирен 6 & 0,20 & 33,6 & 0,65 & $-0,93$ \\
\hline 3. & Бенз (а) антрацен $\boldsymbol{\theta}$ & 0,56 & 70,7 & 1,81 & $-0,88$ \\
\hline 4. & Хризен г & 0,34 & 51,5 & 1,10 & $-1,13$ \\
\hline 5. & Бенз (а) пирен $\partial$ & 0,31 & 52,0 & 1,00 & $-0,86$ \\
\hline 6. & Бенз(е) пирен $e$ & 0,20 & 33,5 & 0,65 & $-1,03$ \\
\hline 7. & Дибенз (а,с) антрацен $e$ & 0,14 & 27,2 & 0,45 & $-0,96$ \\
\hline
\end{tabular}

6. Очищен методом зонной плавки, 6 «Союзхимреактив», $\boldsymbol{\theta}$ «British Drug Houses Ltd.», 2 «Austrowaren, $\partial$ «Fluka AG», $e$ «Gee Lawson Chemicals», 


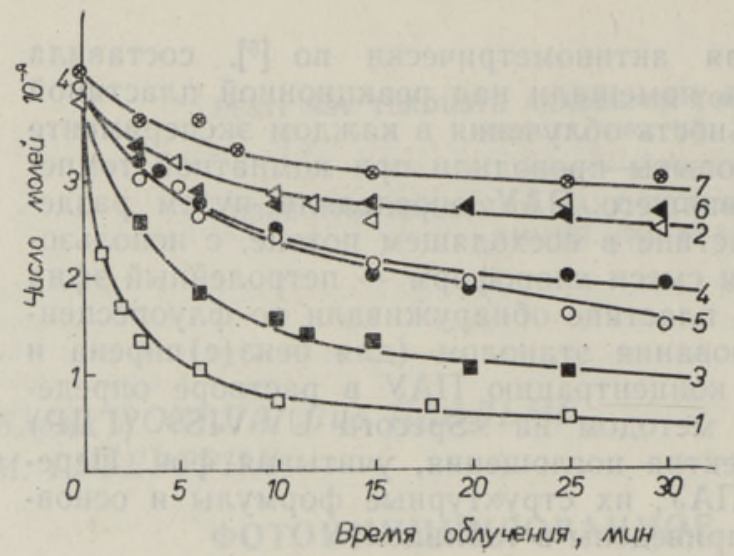

Кинетические кривые фотодеградации разных ПАУ на окиси алюминия. Нумерация соединений по таблице.

ния БП $35-45 \%$ исходного количества; на окиси алюминия соответственно $52 \%$ (см. таблицу). В опециальном контрольном эксперименте в отсутствие носителя степень превращения этого арена при экспозиции 120 мин составляла лишь 45\%. Это обстоятельство, связанное, очевидно, с влиянием развитой поверхности облучаемого объекта и, возможно, природы носителя, качественно свидетельствует о высокой эффективности деградации канцерогена в сходных с природными условиях.

Таким образом, хотя кривые на рисунке достоверно отражают реальную картину деградации изучаемых ПАУ в данных условиях, попытку кинетической оценки влияния молекулярной структуры арена на относительную скорость его фотоинициированного превращения на носителе следует производить по начальной ее величине. Последнюю мы определяли для тех начальных участков кинетических кривых, которые близки к линейным, и скорость деградации рассчитывали по убыли вещества в моль/мин. В таблице приведены относительные показатели, т. е. скорость превращения данного арена, v, отнесенная к скорости превращения БП, $v_{0}$.

Попытка согласовать скорость депрадации аренов разного строения с какими-либо показателями, характеризующими их структуру, оказывается более удачной в том случае, если в качестве определяющего. параметра для корреляции принимается величина потенциала окисления фотовозбужденного состояния молекул $\left(\mathrm{E}_{\mathrm{T}}-\mathrm{E}_{\mathrm{ox}}\right.$, таблица). Выбор этого парамепра определяется сложившейся к настоящему времени концепцией о механизме инициирования и протекания начальной стадии суммарной реакции фотоокисления полиаренов. Очевидно, наиболее вероятным в возникновении реакционной цепи должно быть взаимодействие трипілетно-возбужденного состояния молекул ПАУ с кислородом.

В числе продуктов превращения БПं в реакционной зоне качественно идентифицированы 3,6- и 6,12-хиноны. В заключение укажем, что скорость изменения полициклических ароматических углеводородов, закрепленных на твердых загрязнителях, в процессе фотоинициированного окисления различна, следовательно, часть их может пребывать среди атмосферных загрязнителей длительное время.

\section{Л И Т Р Р А У Р А}

1. Кертес M. Канцерогенные полициклические ароматические углеводороды в загрязнениях атмосферного воздуха в Венгрии (автореф. канд. дис.). М., 1977. 2. Ш а б а д Л. М. О циркуляции канщерогенов в окружающей среде. М., 1973, с, 188. 
3. Ma il a th, F., Medve, F., Mórik, I. A 3,4-benzpirén ultraibolya-és napfénysugárzás hatasára történō lebomlásának kvantitatív tanulmányozása. - Egészségtudomány, 1974 , т. 18 , c. $331-341$.

4. М илукайте А. А. Разработка количественного метода определения полициклических ароматических углеводородов (бенз(а)пирена) -и изучение их миграции в биосфере (канд. дис.). Вильнюс, 1979.

5. B a xendale, J. H., Bridge, N. K. The photoreduction of some ferric compounds in aqueous solution. - J. Phys. Chem. 1955, v. 59, N 8, p. $786-788$.

6. Ренге И. В., Борисевич Ю. Е., Губергриц М. Я., Кузьмин В. А. Взаимодействие триплетных состояний ароматических углеводородов с нитросоединениями. - Доклады АН СССР, 1979, т. 248, № 5, с. 1167-1170.

Ннститут химии
Академии наук Эстонской ССР

Поступила в редакцию $5 / \mathrm{I} 1982$

Ilme ROHTLA, Lia PAALME, M. GUBERGRITS

\section{MONINGATE POLUTSUKLILISTE AREENIDE FOTOINITSIEERITUD LAGUNDAMINE DISPERSSEL TAHKEL KANDJAL}

Artiklis on esitatud andmed benso(a)püreeni ja mõningate teiste viie- ja kuuetuumaliste polütsükliliste areenide lagundamise kohta ultraviolettkiirguse toimel. Kandjana kasutati $1 \mathrm{~mm}$ paksust $\mathrm{Al}_{2} \mathrm{O}_{3}$ kihti, millel uuritava aine kontsentratsioon oli $22,3 \mu \mathrm{g} / \mathrm{g}$.

Leiti, et lähteaine lagunemise kiirus sõltub areeni struktuurist ja hakkab pärast esialgset kiiret faasi asümptootiliselt aeglustuma.

Ilme ROHTLA, Lia PAALME, M. GUBERGRITS

\section{PHOTOINITIATED DEGRADATION OF POLYCYCLIC ARENES ON DISPERSED SOLID CARRIER}

In the present paper data about the UV-initiated degradation of benzo(a)pyrene and some other polycyclic arenes are given. The $\mathrm{Al}_{2} \mathrm{O}_{3}$-layer of $1 \mathrm{~mm}$ thickness was used for carrier, the applied concentration of arene being about $22.3 \mu \mathrm{g} / \mathrm{g}$.

After the initial rapid phase, the decomposition of every arene investigated slowed down, the percentage of destruction depending on its structure. 